\title{
La perspectiva del uso del agua subterránea
}
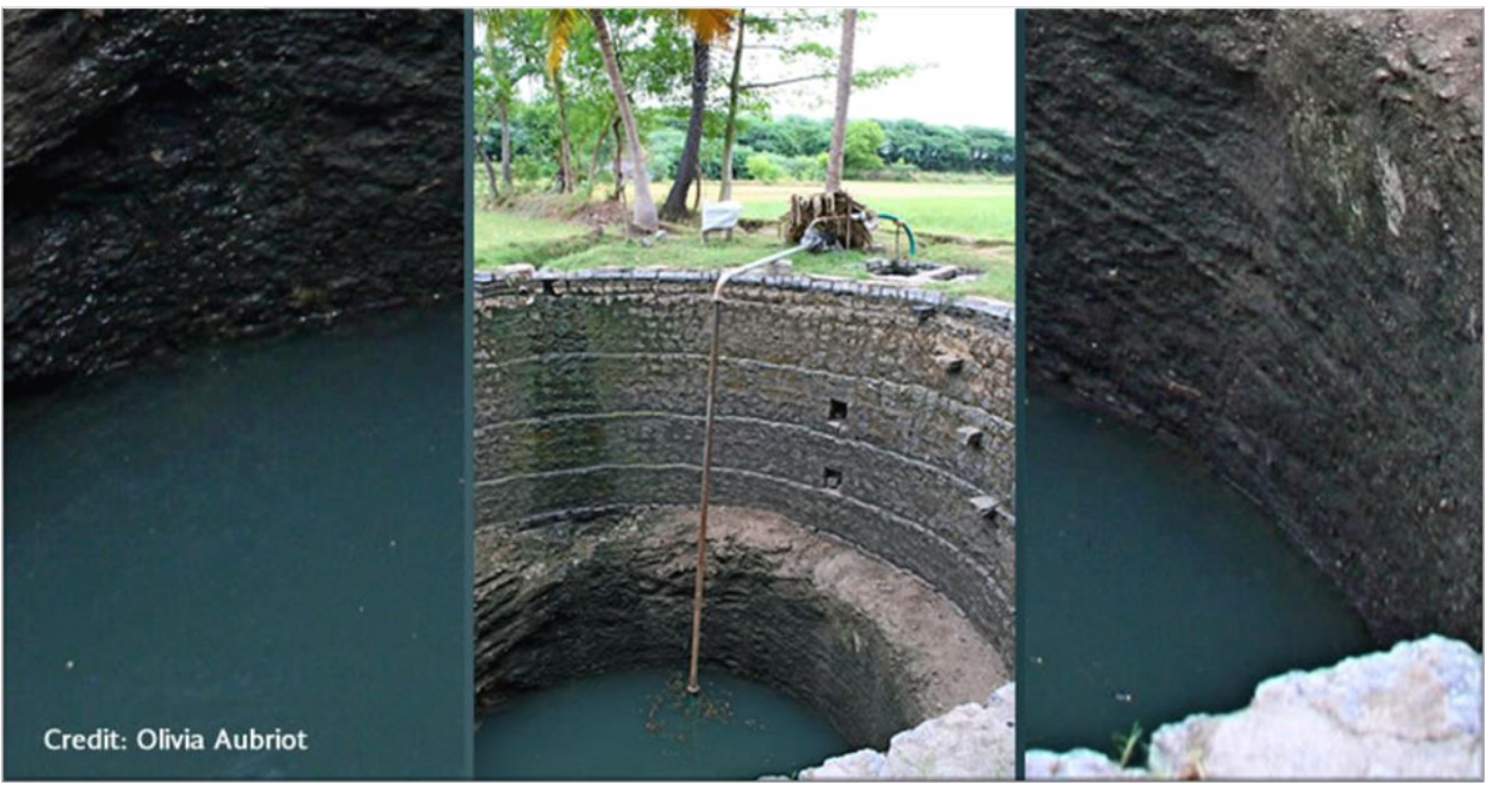

En las últimas décadas, el aprovechamiento del agua subterránea ha desempeñado en todo el mundo un papel predominante en el desarrollo del sector agrícola.

Por ejemplo, se sabe que cerca del $60 \%$ del agua que se utiliza en el sureste asiático para la producción de granos proviene de fuentes subterráneas. El rápido crecimiento en el uso de agua subterránea en estas y otras regiones del planeta ha sido un factor primordial en el incremento de producción de granos, transformando la producción y las estrategias de sustento de millones de pequeños productores que proveen de alimentos a los centros urbanos en pleno crecimiento.

La extracción de una mayor cantidad de agua subterránea motivada por este crecimiento económico ocasiona problemas asociados a la sustentabilidad y la calidad del agua. En India y China, por ejemplo, el abatimiento de los niveles freáticos es muy evidente y pone en cuestionamiento la forma en la que utilizamos y utilizaremos este recurso en el futuro. En otras regiones del mundo, como el Medio Oriente y el norte de África, el excesivo uso de agua subterránea ha incluso caído en el extremo de extraer agua fósil, la cual es considerada como no renovable dada la gran cantidad de tiempo necesaria para su renovación (miles de años). Por esta razón, cualquier uso de agua fósil debe hacerse bajo el amparo de 
una estrategia de desarrollo de largo plazo que considere los impactos que tendrá agotar estas fuentes de suministro en la seguridad de abasto de futuras generaciones. Además del uso de agua subterránea por el sector agrícola, las ciudades y la industria comprenden usuarios adicionales que compiten por esa agua, lo cual hace aún más complicado para pequeños agricultores y comunidades rurales asegurar sus fuentes de abastecimiento. Esto se debe a que el abatimiento de los niveles freáticos por una extracción inmoderada incrementa los costos de operación de los pozos, pues a mayor profundidad de extracción, mayor energía para aprovechar el agua. Por si esto fuera poco, la contaminación inducida por el uso de fertilizantes y nutrientes en el sector agrícola, así como los desechos de las industrias y ciudades por la falta de tratamiento de las descargas, degradan de manera continua el agua contenida en el subsuelo. Además, la alta velocidad a la que estamos extrayendo el agua subterránea tiene también un efecto sobre el gasto base de los ríos, que representa la conexión entre el agua subterránea y superficial, pues comprende la porción del agua subterránea que contribuye al agua que fluye por los ríos. Esto tiene un efecto innegable sobre los ecosistemas ribereños, y un efecto en cascada sobre las comunidades rurales que viven de ellos.

Si bien se reconoce que el problema de sobreexplotación de acuíferos es el más visible, es necesario que, en un contexto de desigualdad social y económica, hagamos también visible el vínculo entre el agua subterránea y su capacidad para generar bienestar y reducir la pobreza. Algunos países del África subsahariana y de Centroamérica nos han dado ejemplos de ello. Sin embargo, incluso en regiones comúnmente asociadas con la sobreexplotación existen áreas con poca utilización. Un ejemplo de lo anterior lo encontramos en la parte este de la India, donde casi no se ha desarrollado el uso de agua subterránea.

Los problemas de gestión del agua subterránea en el mundo en vías de desarrollo no son únicos por región. Sin embargo, en estos países, esta gestión sí pone sobre la mesa un conjunto de retos únicos asociados con este elemento. En contraste con el agua superficial, el agua subterránea no se ve, es “invisible” y, por lo tanto, esto hace más complicada su conceptualización y medición. Más aún, es muy importante que entendamos que las escalas de tiempo a las que fluye el agua en el subsuelo son mucho mayores a aquellas que se aprecian a simple vista en un río o en la lluvia, y que además existe un retraso temporal entre la incidencia de una tormenta y la recarga de un acuífero. Por ello, es mejor pensar la relación entre la lluvia, el almacenamiento del agua en los acuíferos y el uso de esta a través de las extracciones en escalas temporales, ya sea en términos de años, décadas o incluso siglos. Es posible afirmar que el agua subterránea es un recurso de acceso abierto. Un acuífero con niveles freáticos cerca de la superficie, ubicado debajo de varias granjas de pequeños productores, se convierte en una fuente de fácil acceso para cualquiera de ellos, quienes pueden extraer el agua con tecnología de bombeo relativamente barata. En muchos países densamente poblados, esto significa que la gestión del agua requiere la coordinación de cientos e incluso miles de usuarios, una característica que hace más complicada para todos, usuarios y gobierno, la coordinación y medición de los acuíferos.

Para hacer frente de manera exitosa a los retos relacionados con el agua subterránea es fundamental entender la física de su movimiento y medirla, pero también debemos entender la sociología de los usuarios del agua y la economía política de los sectores hídrico y agrícola. El reto es mayúsculo. Lo que se encuentra en juego es el futuro de nuestros hijos y nietos. En el IMTA estamos seguros de que el uso adecuado del agua es la llave de acceso para reducir la pobreza. Sin embargo, como vemos en todo el mundo, para hacer de esto una realidad es necesario revisar con detalle aquello que no ha funcionado o que ha resultado incompleto. En el caso del agua subterránea, una de las posibilidades señaladas ya desde hace tiempo por este Instituto es el reconocimiento de los acuíferos como unidades regionales de flujo, lo que implica una nueva delimitación de acuerdo con la hidrogeología local, es decir, con la 
PERSPECTIVAS IMTA (0)

$\mathrm{N}^{\circ} .23,2020$

Autor: Adrián Pedrozo Acuña

DOI: doi.org/10.24850/b-imta-perspectivas-2020-23

realidad del subsuelo. Además, es urgente avanzar en la actualización de la metodología para el cálculo de la disponibilidad y recarga de estos sistemas, lo que nos permitirá caminar hacia la estabilización de acuíferos sobreexplotados y la conservación de aquellos en los que todavía existe disponibilidad.

Foto: Open well and pump, India.

Autora: Oliva Aubriot

Creative Commons 